\title{
Evolución de las microfinanzas desde la perspectiva de la financiarización
}

\author{
Diego Alejandro Guevara Castañeda \\ Universidad Nacional de Colombia \\ Colombia
}

Natalia Ramírez Virviescas Universidad Nacional de Colombia

Colombia

Alejandra Rodríguez Mejía Universidad Nacional de Colombia

Colombia

Sofia Salamanca Ballesteros Universidad Nacional de Colombia Colombia

María Paula González Rodríguez Universidad Nacional de Colombia Colombia 


\title{
Evolución de las microfinanzas desde la perspectiva de la financiarización
}

\author{
Diego Alejandro Guevara Castañeda ${ }^{1}$, Natalia Ramírez Virviescas ${ }^{1}$ (D), \\ Alejandra Rodríguez Mejía ${ }^{1}$ (D), Sofia Salamanca Ballesteros ${ }^{1}(\mathbb{D})$ y María Paula \\ González Rodríguez ${ }^{1}$. \\ ${ }^{1}$ Universidad Nacional de Colombia - Colombia
}

Para citaciones: Guevara, D., Ramírez, N., Rodríguez, A., Salamanca, S. y Gonzalez, M. (2020). Evolución de las microfinanzas desde la perspectiva de la financiarización. Panorama Económico, 28(3), 159-181. https://doi.org/10.32997/pe-2020-2699

Recibido: 20/10/2019

Aprobado: 08/01/2020

Autor de correspondencia:

Diego Alejandro Guevara Castañeda

dieguevarac@unal.edu.co

Proyecto de Investigación: Evaluación de las microfinanzas en Mocoa en la última década desde la perspectiva de la financiarización y el impacto del desastre natural sobre los deudores financiado por la Universidad Nacional de Colombia.

Editor: Andrés Escobar Espinoza Universidad de Cartagena, Colombia.

Tipología IBN Publindex:

Artículo de Reflexión

Copyright: () 2020. Guevara, D., Ramírez, N., Rodríguez, A., Salamanca, S. y Gonzalez, M. Este es un artículo de acceso abierto, distribuido bajo los términos de la licencia https://creativecommons.org/licenses/bync-sa/4.0/ la cual permite el uso sin restricciones, distribución y reproducción en cualquier medio, siempre y cuando que el original, el autor y la fuente sean acreditados.

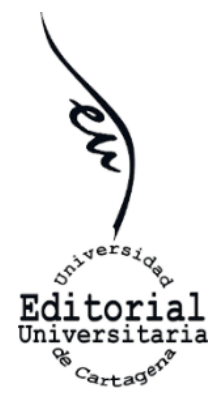

\section{RESUMEN}

Con el propósito de robustecer la inclusión financiera, apoyar proyectos productivos en el sector agropecuario, fomentar la formalidad y, en consecuencia, contribuir a la superación de la pobreza; las microfinanzas han desempeñado un importante rol en la economía de municipios colombianos como Mocoa, capital del departamento de Putumayo, ubicada al sur del país. Sin embargo, la configuración particular del modelo microfinanciero puede tornarse muy compleja en situaciones de desastres naturales, especialmente cuando las leyes que cobijan este modelo son permisivas con los lineamientos de cobro, la flexibilización de los pagos y la evaluación de proyectos productivos, dejando muchas veces desprotegido al usuario y permitiendo que el fin social del microcrédito se distorsione y se convierta en un propósito netamente rentístico que aumenta la vulnerabilidad social y económica. A partir de un análisis en el que se implementa una metodología de investigación mixta, se observa que el modelo microfinanciero implementado en Mocoa entre 2007 y 2017, está permeado por escenarios de sobreendeudamiento, precariedad en la educación financiera de los habitantes, y ausencia total de la implementación de alguna metodología microfinanciera, lo cual resulta en leves manifestaciones de un proceso de financiarización, y un obstáculo para la recuperación de la economía del municipio.

Palabras clave: Microfinanzas, desastres naturales, financiarización. Códigos JEL: G21, H84, G29

\section{Evolution of microfinance from the perspective of financialization}

\begin{abstract}
With the purpose of strengthening financial inclusion, supporting productive projects in the agricultural sector, promoting formality and, consequently, contributing to overcoming poverty; Microfinance has played an important role in the economy of Colombian municipalities such as Mocoa, capital of the Putumayo department, located in the south of the country. However, the particular configuration of the microfinance model can become very complex in situations of natural disasters, especially when the laws that cover this model are permissive with the collection guidelines, the flexibility of payments and the evaluation of productive projects, often leaving unprotected to the user and allowing the social purpose of the microcredit to be distorted and become a purely profit-making purpose that increases social and economic vulnerability. From an analysis in which a mixed research methodology is implemented, it is observed that the microfinance model implemented in Mocoa between 2007 and 2017 is permeated by scenarios of over-indebtedness, precariousness in the financial education of the inhabitants, and total absence of the implementation of some microfinance methodology, which results in slight manifestations of a financialization process, and an obstacle to the recovery of the municipality's economy.
\end{abstract}

Keywords: Microfinance, natural disasters, financialization.

Códigos JEL: G21, H84, G29 


\section{INTRODUCCIÓN}

En Colombia, un desastre natural de gran magnitud y con gran impacto sobre el desarrollo económico se dio con la denominada "Tragedia de Mocoa". Mocoa, capital del departamento de Putumayo, es un municipio de desarrollo intermedio con 43.731 habitantes, un índice de ruralidad del 79,7\% y un índice de pobreza correspondiente al 52,6\%1, que se manifiesta a la par con problemáticas sociales tales como el establecimiento de cultivos con fines ilícitos en áreas de difícil control, y el desplazamiento de población desde diferentes partes del departamento por la presencia de grupos armados enfrentados por el control del territorio y de los cultivos ilícitos (Municipio de Mocoa, s.f.).

Mocoa tiene una participación del $1 \%$ en el PIB nacional, como principal actividad económica se destaca el comercio, con el 49,3\% de la participación en las actividades económicas no ligadas con la vivienda, y de acuerdo con la Cámara de Comercio del Putumayo para el año 2013, el 92,3\% de las unidades económicas del municipio se clasificaban como microempresas. Con respecto a la cobertura en la oferta de servicios financieros, para el 2017, se destacaba la fuerte articulación entre estos servicios y las actividades ligadas al comercio y a los servicios. A pesar de la relevancia a nivel municipal del Banco Agrario, sobresalen alternativas como los fondos comunitarios, como es el caso de la Asociación de Ganaderos de Mocoa, Asogam (PNUD, 2015).

La participación de las actividades financieras y de seguros, en el PIB del departamento de Putumayo, entre 2016 y 2018 se mantuvo constante, siendo 1,5\% en 2016 y 1,6\% en 2017 y $2018^{2}$ (DANE, 2019). Por otra parte, el valor agregado ${ }^{3}$ del municipio de Mocoa a precios corrientes en el año 2016 fue de 607 miles de millones de pesos, lo que significa un peso relativo municipal en el valor agregado departamental del 19\%. En el año 2017, el valor agregado fue de 634 miles de millones de pesos y en consecuencia su peso relativo fue del 18,4\% (DANE, 2019). Frente a la composición empresarial del municipio, se debe destacar que, en el año 2014, ante la Cámara de Comercio de Putumayo, había un total de 1.664 empresas renovadas y matriculadas, y 177 entidades sin ánimo de lucroESALES (CC del Putumayo, 2015). En el año 2017, el número de renovaciones y matrículas aumentó a 2.156 personas naturales y 325 personas jurídicas. En el caso de ESALES, el número aumentó a 234, además se contaba con 2187 establecimientos de comercio renovados y matriculados (CC del Putumayo, 2019).

La realidad de Mocoa, las actividades productivas del municipio, así como el día a día de sus habitantes se vieron enormemente afectadas por lo que se ha denominado "La tragedia de Mocoa". El 31 de marzo de 2017 se presentaron fuertes lluvias que provocaron deslizamientos, deslaves y flujos de lodo en las cuencas altas de los ríos Mocoa, Mulato y Sancoyaco. Estos desbordamientos arrasaron varios sectores urbanos en el municipio de Mocoa causando un desastre que destruyó viviendas, establecimientos de comercio, puentes, redes de servicios públicos, vehículos, pero más allá de aspectos de infraestructura, la tragedia cobró al menos 332 personas fallecidas, más de 398 heridos y

1 Proyecciones del Censo de 2005 del DANE (2019).

2 El PIB del departamento de Putumayo, en el año 2016 correspondía a 3.298 miles de millones de pesos (a precios corrientes), en 2017 (año de la avalancha) el PIB fue de 3.575 y en 20183.983.

${ }^{3}$ Diferencia entre el valor de la producción bruta y los consumos intermedios empleados. 
un total de 22.310 damnificados en más de 48 barrios consignados en el registro único de damnificados RUD (DNP, 2017) y una cifra no oficial de 300 desaparecidos (Duque, 2017).

El desastre convulsionó la vida, rutina y actividad productiva de la población, por lo cual se decretó estado de emergencia económica, social y ecológica el 6 de abril de 2017 por medio del Decreto 601 del 6 de abril de 2017 emitido por la presidencia de la República y el Decreto 068 y 056 del mismo mes emitidos por la gobernación de Putumayo y la alcaldía de Mocoa respectivamente. El 3 de abril de 2018, la presidencia de la República decretó la prórroga de la situación de desastre en Mocoa por un año más, previa recomendación del Consejo Nacional para la Gestión del Riesgo. A raíz de la avalancha se desencadenaron importantes problemáticas socioeconómicas en la población, dentro de las cuales se destaca la falta de empleo de los supervivientes, se estima que prácticamente la totalidad de los pequeños empresarios de Mocoa quedaron afectados: $41 \%$ de ellos tuvieron pérdida total de su negocio y el 59\% sufrieron pérdidas parciales. Entre estos, los usuarios de productos microfinancieros vieron de un momento a otro como la avalancha había destruido sus negocios, más del 40\% del municipio quedó destruido y la reconstrucción económica y social del mismo era un tema aún más desafiante que la reconstrucción de viviendas o reactivación de los servicios básico como agua o luz (Duque, 2017).

Tomando en consideración que el impacto de un desastre natural sobre las finanzas de una población es un tema de investigación todavía en desarrollo, en particular cuando se busca analizar el efecto sobre las microfinanzas, la presente investigación pretende abordar este análisis por medio de la implementación de un método mixto por medio del cual se realiza una revisión de la literatura y se ahonda con entrevistas de profundización, para luego analizar datos cuantitativos de fuentes oficiales y datos obtenidos por medio de una encuesta local, para finalmente obtener un análisis que describa tal impacto.

\section{EI DEBATE SOBRE LAS MICROFINANZAS}

Como lo indican Gutiérrez y Unceta (2015), las instituciones microfinancieras tienen dos aproximaciones debido a su característica social por la que fueron creadas. La primera es la responsabilidad social que implica un mínimo de transparencia en sus acciones, contribuir a la oferta de servicios financieros y evitar los efectos negativos en los agentes de la sociedad. A esta se le agrega la aproximación de desempeño social, que tiene como objetivo traducir a la práctica la misión social de estas instituciones, que es mejorar el bienestar de los pobres permitiendo potenciar sus capacidades productivas.

Muhammad Yunus advirtió que los créditos debían ser acompañados por educación financiera e ideas de emprendimiento para lograr un verdadero aumento de bienestar en la población, ya que promueve la formalización y creación de empresa. Por ende, la inversión en capital es la finalidad de los microcréditos lo cual aumenta los factores productivos y logra el desarrollo, específicamente el Bottom Up. Esta tendencia promueve proyectos productivos individuales en la población de bajos recursos para desarrollar empresas, los cuales desde una perspectiva virtuosa del desarrollo microfinanciero han 
de estar acompañados por tecnologías de grupo y seguimiento permanente al proyecto productivo.

Con tales fines, las instituciones microfinancieras (IMF) se convierten en promotoras del desarrollo mejorando la competitividad y productividad tanto de las empresas formales como de las informales, siempre y cuando se tenga garantía del impulso que le puedan dar a la superación de la pobreza, por lo que se debe contar de manera articulada con la participación del gobierno mediante propuestas y estrategias de desarrollo que contribuyan a generar riqueza y valor en los municipios y fomentar la inversión en capital de trabajo y activos fijos, para de esta manera impulsar el desarrollo a la vez que pueden enfrentar la pobreza rural con éxito (Ramírez, 2018). Autores críticos frente a las microfinanzas como Bateman, argumentan que éticamente no resulta correcto la promoción del microcrédito, ya que en el fondo está la idea de enriquecerse del endeudamiento de los pobres, lo que contradice su contribución al desarrollo sostenible. Además, se evidencian casos en los cuales, dado que las IMF han mostrado altos rendimientos por las tasas de interés cobradas y el alto índice de reembolso, diferentes instituciones financieras tradicionales han decidido incursionar en las microfinanzas. Esto ha hecho que los bancos microfinancieros reorienten su propósito dejando de lado los fines sociales en pro de generar rendimiento para los accionistas y socios, como por ejemplo ocurrió con el caso de Bancosol en Bolivia, tras incursionar en el mercado de capitales.

Desde esta perspectiva se asegura que las microfinanzas no son necesariamente un instrumento para atacar la pobreza, ni para generar desarrollo. Por el contrario, se asocia a las microfinanzas con la desindustrialización e informalización que aumentan hasta el punto de destruir la capacidad de incrementar la productividad y en este sentido imposibilitan el desarrollo sostenible, el crecimiento y la reducción de la pobreza en el largo plazo. Además, no solo imposibilita el desarrollo, sino que profundiza la pobreza, inequidad y el rezago (Bateman, 2013). La pérdida de los objetivos sociales por los que las microfinanzas fueron creadas genera los efectos mencionados anteriormente. Esto se denomina financiarización de las microfinanzas, es decir: "(...) conversión de los servicios microfinancieros hacia un enfoque netamente rentístico, en el cual se desdibuja la metodología microfinanciera y en consecuencia se generan escenarios de sobreendeudamiento, cobros por encima de la tasa de usura, acciones coercitivas para la recolección de cartera, entre otros aspectos que desencadenan una mayor vulnerabilidad económica y social de la población." (Ramírez, 2018, p. 16).

La financiarización de las microfinanzas se caracteriza por un uso inadecuado de los recursos otorgados mediante la figura de microcrédito, lo cual desencadena problemas del endeudamiento, ya que, en lugar de emplearse como inversión productiva en capital, se han destinado a resolver problemas de liquidez inmediata, como ha ocurrido en Perú y México (Soto Esquivel, 2017). También se caracteriza por el cobro de tasas de interés por encima de las tasas de usura permitidas y ligado a ello con el uso de tácticas de cobro coercitivo por parte de las instituciones microfinancieras. En Colombia, Ramírez (2018) argumenta que, ante la carencia de un marco regulatorio que proteja a los usuarios, se vislumbran rasgos propios de un proceso de financiarización de las microfinanzas a raíz de la alta permisividad en cuanto a la flexibilidad de los pagos, los lineamientos de cobro y la evaluación de proyectos productivos. En este contexto, se desdibuja el fin social de 
las microfinanzas y se torna en uno netamente rentístico que profundiza la vulnerabilidad social y económica de la población.

\section{Desastres Naturales y las Microfinanzas}

Debido al nicho de las microfinanzas, la vulnerabilidad ante los desastres naturales se hace más fuerte comparada con los riesgos que asume el sistema financiero tradicional. Tal como lo expone Naomi Klein (2007), este tipo de episodios traumáticos son vistos y aprovechados por muchos para promover e implementar cambios estructurales a nivel económico, político y social. Basta ilustrar con los casos de Sri Lanka y Tailandia, donde luego de sufrir una catástrofe natural, se implementaron políticas regresivas que no tomaban en cuenta el bienestar de los ciudadanos damnificados.

Ante la problemática estudiada en esta investigación, es necesario tener antecedentes ante acciones que han tomado instituciones microfinancieras para hacer frente a la vulnerabilidad de sus clientes en este tipo de situaciones. Dos antecedentes de relevancia se describen en los estudios de Shoji (2012) y Ullah et al. (2007), los cuales investigan la inundación en Bangladesh en 2004 y el terremoto en Pakistán en 2005, respectivamente. En los dos casos se desarrolla un estudio sobre las acciones tomadas por IMF como respuesta ante estas catástrofes. Ante la catástrofe, existió un retraso de los pagos en las zonas afectadas, el cual era un 52\% mayor que en las zonas no afectadas. Por ende, se desarrolló una estructura de reembolso, la cual da paso a una reprogramación de pagos y depósitos semanales durante estos desastres sin cobrar tasas de interés adicional. Se pudo observar que el sistema de reembolso no afecta el ingreso de los beneficiados en el largo plazo, pero se tiene una dotación de recursos intertemporales que eran más altos entre más largo fuera el periodo del reembolso. Por esto, se permite aliviar transitoriamente la pobreza y reducir la restricción de los créditos, pero controlando el sobreendeudamiento.

Las conclusiones son positivas, el sistema de pagos es una red de protección que ayuda a tener resultados para la mitigación de la pobreza cuando hay choques negativos. Además, permite a las personas afianzarse con este sistema ya que no deben costear el reembolso y permite estabilizar estas instituciones. Finalmente, en relación con las implicaciones políticas, los autores señalados afirman que es importante proteger a los consumidores con microseguros e invertir en capital humano diversificado en amplias regiones porque permite prevenir el choque local que afecte el nuevo sistema de pago. Shoji (2010), se cuestionó por el rol del sistema de pago contingente introducido en 2002 en las microfinanzas de Bangladesh, que permitía la reprogramación de ahorros y cuotas durante desastres naturales para los usuarios afectados de la mano con un mecanismo de seguro. Su investigación concluye que, tras las inundaciones de 2004, este mecanismo tuvo un efecto muy positivo, en especial sobre las mujeres y usuarios sin propiedades, y que, en consecuencia, se configuró como un aspecto que refuerza el papel en la reducción de la pobreza por parte de las microfinanzas. En particular, el estudio de Shoji (2010), encuentra que la reprogramación de los pagos ayudó a las víctimas de la inundación en Bangladesh a asegurar su consumo de comida, en tal sentido, la reprogramación se asoció con una reducción en el 5,1\% de la probabilidad de saltar comidas durante los shocks negativos. De allí que se destaque el rol de las microfinanzas en la reducción de la pobreza y es más específicamente, en las dinámicas de un consumo suavizado (Shoji, 2010). 
Kumar y Newport (2007), muestran la forma como las microfinanzas han contribuido a la reducción de la pobreza y al fortalecimiento del manejo del riesgo por parte de personas en situación de pobreza. Este análisis destaca la importancia para las instituciones microfinancieras de preparar una estrategia que permita mantener la liquidez en situaciones como puede llegar a ser un desastre natural, en especial, manteniendo fondos de préstamos para desastres en reserva con el fin de ayudar a los hogares afectados.

\section{MICROFINANZAS EN MOCOA TRAS EL DESASTRE DE 2017}

\section{Oferta de Servicios Financieros en Mocoa}

Con el propósito de desarrollar un enfoque mixto de investigación, el presente artículo parte de analizar cuantitativamente el desenvolvimiento financiero en el municipio de Mocoa, tomando como base el conocimiento del estado actual de bancarización en Colombia, el cual a 2018 cubre más de 1.102 municipios en el país, abarcando así la totalidad del territorio colombiano, y ampliando la presencia en zonas rurales, a la vez que se cumplen con indicadores alentadores sobre la financiación de las microempresas. Para 2017, 3.544.150 microempresarios accedieron al microcrédito, pero se sigue teniendo el 63\% de la población desatendida. La cartera de crédito cerró en 2018 con $\$ 434$ billones, de los cuales 14.05 corresponden a la modalidad de microcrédito (Asomicrofinanzas, 2018).

Frente a la oferta de servicios financieros en Mocoa, la cobertura del sistema financiero aumenta en promedio más del 100\% anual de acuerdo con la tendencia mostrada en cifras de la Superintendencia Financiera de Colombia (Ramírez, 2018) y está especialmente relacionada con actividades de comercio y ligadas con los servicios. La principal entidad que ofrece programas de crédito al sector agropecuario es el Banco Agrario. Según lo señalado por el Reporte de Inclusión Financiera de 2016, Putumayo se ubicaba en dicho año como uno de los 18 departamentos con el indicador de número de oficinas por cada 100.000 habitantes por debajo del promedio nacional con un valor igual a 24,3. Adicionalmente, su indicador de inclusión financiera (porcentaje de adultos con productos financieros) se encontraba por debajo del 60\%, ubicándose entre los 10 departamentos con menor inclusión financiera.

Cabe señalar que Putumayo se encontraba en 2016 entre los primeros 5 departamentos con mayor porcentaje de adultos con un microcrédito vigente. Con respecto a Mocoa, no se tiene el porcentaje exacto, sin embargo, los municipios catalogados como intermedios, como es su caso, presentaban un porcentaje promedio igual a 13,1\%. En marzo de 2017, en Mocoa se reportaba presencia de dos cooperativas SES 4: Cooperativa De los Trabajadores De La Educación y Empresarios del Putumayo, y la Cooperativa Latinoamericana de Ahorro y Crédito; 8 oficinas de entidades bancarias: Banco Agrario, Bancamía S.A, Banco Mundo Mujer S.A, Banco Popular, Bancolombia, Bancompartir S.A, BBVA Colombia y WWB S.A; y dos ONG especializadas en la colocación de microcrédito: Contactar ${ }^{5}$ y Fundación de la Mujer (Banca de las Oportunidades, 2017).

\footnotetext{
${ }^{4}$ Entiéndase por Cooperativas vigiladas por la Superintendencia de Economía Solidaria (SES), aquellas cooperativas de ahorro y crédito cuya función principal consiste en adelantar actividad financiera exclusivamente a sus asociados.

${ }^{5}$ Bancóldex en comunicado del 14 de marzo de 2018, resaltó el reconocimiento entregado a la microfinanciera Contactar que presta sus servicios en Putumayo por la colocación de $\$ 45.000$ millones de pesos entre 2017 y 2018, a través de créditos Bancóldex, y también por el acompañamiento a las empresas del municipio de Mocoa afectadas por la avalancha.
} 
De acuerdo con el análisis de la información suministrada por la Superintendencia de Economía Solidaria (SES) sobre las entidades que vigila para el período comprendido entre 2007 y 2017, se destaca que el promedio ponderado de la tasa para microcrédito en el departamento de Putumayo para 2009 y 2010 (únicos años con información) superaba en más de 2 puntos porcentuales a la tasa promedio nacional, alcanzando el 20 y $21 \%$ respectivamente, pero sin superar la tasa de usura (SES, 2018). Frente a aquellas entidades reguladas y vigiladas por la Superintendencia Financiera de Colombia (SFC), se puede observar una tendencia creciente de la cartera de microcrédito en Putumayo desde el 2007 hasta el 2017. En el 2017 alcanza el punto máximo del periodo de estudio en 47.943.306 millones de pesos, en este mismo año la tendencia se revierte y refleja un comportamiento decreciente que se mantiene hasta el 2018 (Ver figura 1).

Figura 1: Cartera microcrédito Putumayo (2007-2018) en millones de pesos

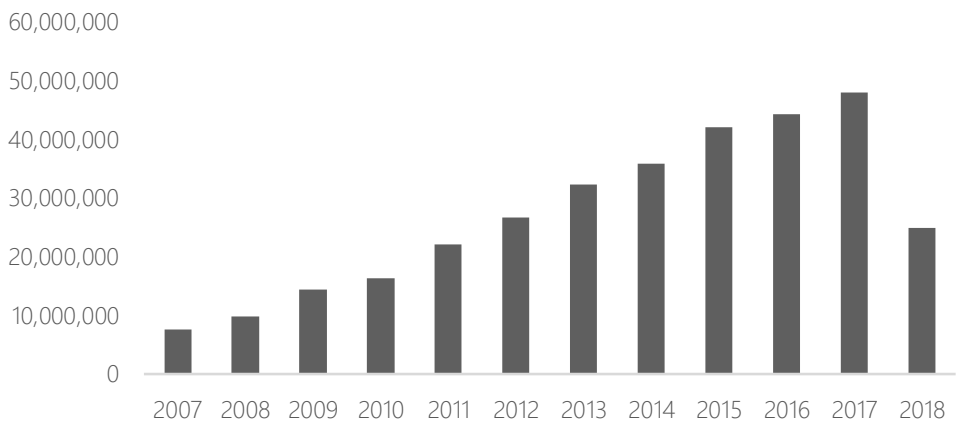

Fuente: Superintendencia Financiera de Colombia (2018). Elaboración propia.

Con respecto a la proporción de la cartera de microcrédito sobre la cartera bruta en Putumayo, en las entidades vigiladas por la SES, en el periodo de análisis no se observa un valor superior a 0,00 salvo en 2010 cuando la proporción fue igual a 0,44. En contraste, a nivel nacional esta proporción pasó de ser igual a 2,09 en 2007 a 4,48 en 2017 (SES, 2018). La participación de la cartera correspondiente a microcrédito sobre la cartera neta de Mocoa ha tenido un notable crecimiento entre 2007 y 2018 como se puede apreciar en la figura 2. La participación de la cartera de microcrédito sobre la cartera neta de Mocoa supera levemente el 5\% en 2007, este comportamiento se mantuvo hasta 2014, sin embargo, a partir de 2015 superó el 10\% y ha mantenido una tendencia positiva en tal crecimiento. Es importante resaltar que entre 2017 y 2018 la participación se mantuvo constante (Ver Figura 2).

Figura 2: Participación cartera de microcrédito sobre la cartera neta Mocoa, 2017-2018.

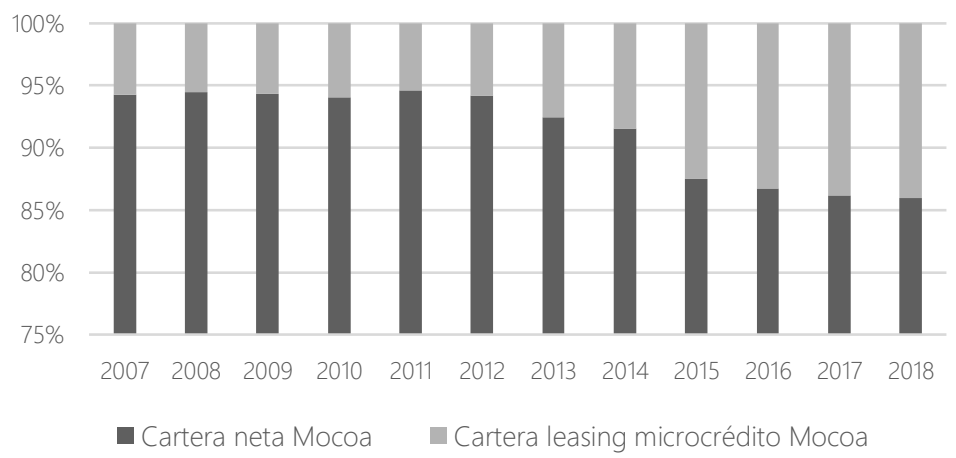

Fuente: Superintendencia Financiera de Colombia (2018). Elaboración propia. 
Por otra parte, según los datos suministrados por la Superintendencia Financiera de Colombia (2017), dentro de los 22.310 damnificados inscritos en el RUD después de la catástrofe del 31 de marzo del mismo año había un total de 5.722 créditos otorgados, siendo la modalidad de microcrédito quien tenía más del 50\% de participación sobre este total. El crecimiento de las microfinanzas en Mocoa se evidencia en el comportamiento de la cartera (Ver figura 3). Este indicador no tiene un comportamiento diferente al del departamento, muestra que los créditos otorgados bajo la modalidad de microcrédito han tenido una tendencia creciente desde el 2012, tendencia positiva que se hace aún más marcada en el 2014.

Figura 3: Cartera de microcrédito Mocoa en millones de pesos, 2007-2018.

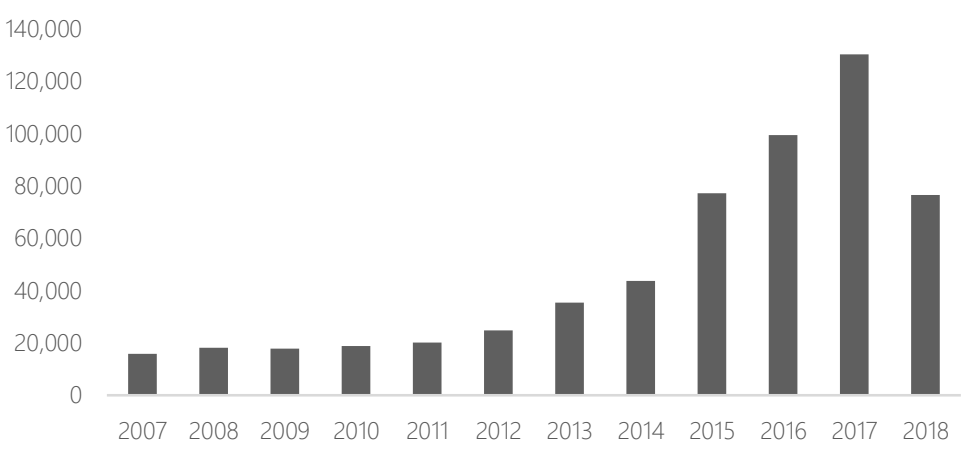

Fuente: Superintendencia Financiera de Colombia (2018). Elaboración propia.

En cuanto a la morosidad de los microcréditos en Mocoa se puede observar que tiene un comportamiento regular entre 2007 y 2013 (Ver figura 4). Después del 2013 la morosidad empieza a reflejar una tendencia creciente y es en el segundo y tercer trimestre de 2017, cuando se alcanza el pico más alto, lo cual coincide con la ocurrencia de la avalancha.

Figura 4: Índice trimestral de morosidad microcrédito Mocoa en millones de pesos, 2007-2018

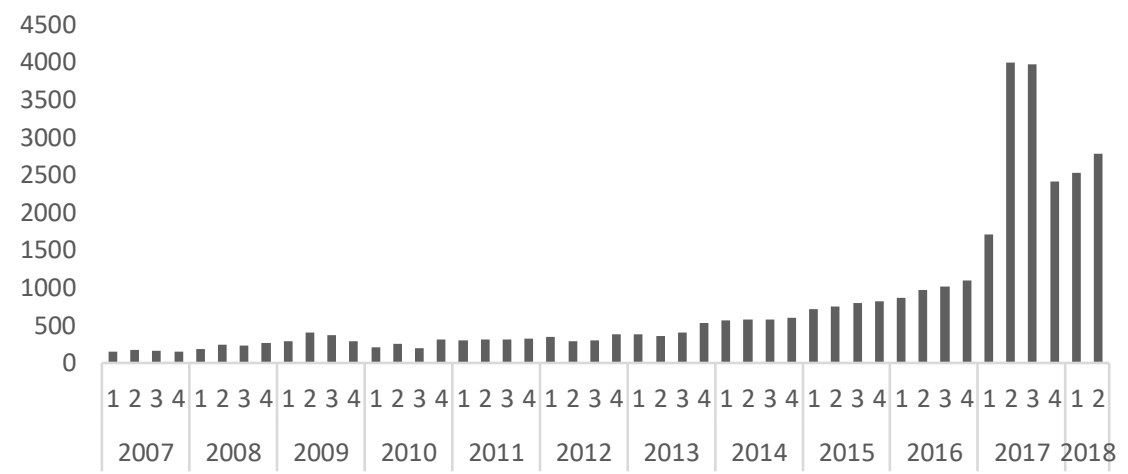

Fuente: Superintendencia Financiera de Colombia (2018). Elaboración propia

\section{LA TRAGEDIA DE MOCOA DESDE LA PERSPECTIVA DE FINANCIAMIENTO}

Al analizar el efecto de la avalancha del 2017 en Mocoa sobre las microfinanzas, se puede observar que, de acuerdo con la recolección de datos de la SFC, la cartera encuentra su punto máximo en el lapso de estudio durante el año 2017, momento en el cual alcanzó 
130.205 millones de pesos, siendo este año el de la tragedia. A pesar de lo que se podría suponer, luego de este pico la conducta de la cartera es contraria a la tendencia, ya que muestra un comportamiento decreciente (Ver figura 3). En cuanto a la morosidad de la cartera de microcrédito en Mocoa se tiene que la tendencia creciente es aún más marcada en el primer trimestre de 2017, lo cual corresponde también al periodo en el cual ocurre la tragedia. En los dos primeros trimestres de 2017 la tasa de crecimiento del índice de morosidad es de $56 \%$ y $134 \%$, tasas de crecimiento muy superiores al promedio registrado antes de la catástrofe. Este dato muestra que la avalancha de marzo de 2017 en Mocoa está relacionada negativamente con el pago de los microcréditos (Ver figura 4), observación que resulta intuitiva dado el impacto a nivel socioeconómico. Así mismo, es importante resaltar la caída de esta tendencia creciente en el cuarto trimestre del 2017, esto producto de las ayudas anunciadas en la Circular Externa 009 de la Superintendencia Financiera de Colombia del 5 de abril del 2017, con la cual se dictaron los lineamientos para atender la emergencia. Sin embargo, es claro que el comportamiento de morosidad sigue siendo mucho más alto que el observado antes de la tragedia.

Con respecto a las acciones tomadas por parte del Estado en respuesta a la tragedia, se destaca el documento CONPES 3904 por el cual se reglamenta el plan de reconstrucción del municipio de Mocoa durante los siguientes 5 años (2017-2022). Este documento fue emitido el 31 de octubre del año 2017 por parte del Departamento Nacional de Planeación y los Ministerios de Vivienda, Ciudad y Territorio, el Ministerio Hacienda y Crédito Público y el Ministerio de Defensa Nacional, quienes establecieron 6 líneas de acción estratégicas: Ordenamiento territorial, ambiente y gestión de riesgo, Infraestructura social, Conectividad e integración regional, Desarrollo económico y Desarrollo institucional. Las proyecciones de financiación de este plan de acción suma un total de 1.181.433 millones de pesos corrientes (DNP,2017).

Dentro de la línea de desarrollo económico se pretende primero, la reubicación y reconstrucción de la plaza de mercado, seguido de acciones por parte del Ministerio de Comercio, Industria y Turismo para apoyar a 170 empresarios que fueron afectados por la avalancha del 31 de marzo. Las acciones comprenden desde cofinanciación, equipos, el montaje y asesoramiento técnico. A su vez se establece que la Unidad Administrativa Especial de Organizaciones Solidarias apoyará iniciativas solidarias con la asesoría técnica en proyectos productivos. Por otro lado, se incluye el fomento a la generación de empleo por parte de Invías. De manera paralela al diseño del CONPES, a lo largo del 2017 se recibieron donaciones de diferentes procedencias. En abril de 2017, tras las reuniones del Grupo BID en Paraguay, el gobierno colombiano recibió US\$200.000 de donación para apoyar las labores de atención de la emergencia en Mocoa (Ministerio de Hacienda, 2017). Según cifras recolectadas por la Unidad Nacional para la Gestión del Riesgo de Desastres de Colombia en el 2018; el municipio de Mocoa recibió en el 2017, donaciones tanto internacionales como nacionales que sumaban en especie y en efectivo 37.673 millones de pesos.

Dado el impacto sobre las actividades productivas, en mayo de 2017, se anunció que, con el respaldo del Ministerio de Comercio, Industria y Turismo, los beneficios y ayudas económicas que se establecieron para quienes lo perdieron todo en Mocoa, se ampliarían a quienes perdieron más del $70 \%$ de sus negocios. 
En este sentido, el gobierno señaló que tenía una base de datos de más de 2.000 comerciantes que se encontraban categorizados y caracterizados para poder obtener los tres tipos de ayuda previstos, además, se indicó que 354 comerciantes estaban inscritos en la Cámara de Comercio, donde se darían ayudas para generar un apoyo económico (MinComercio, Industria y Turismo, 2017).

Entre otras acciones expuestas por la Ministra de Comercio en su visita a Mocoa un mes después de la tragedia, se destacó la opción de acceder por parte de los comerciantes a una línea de crédito con una tasa especial, un año de periodo de gracia y cinco años completos de crédito; el acompañamiento a los comerciantes a trabajar con las microfinancieras y con los bancos, con el apoyo del equipo del Ministerio, sobre lo cual resaltaban como resultado que la gran mayoría de estas entidades otorgarían 6 meses de plazo muerto para los intereses de capital (MinComercio, Industria y Turismo, 2017).

En el Decreto 658 de 2017 del Ministerio de Comercio, Industria y Turismo, "Por el cual se dictan medidas dentro del estado de emergencia económica, social y ecológica para incentivar la actividad económica y la creación de empleo en el municipio de Mocoa, departamento del Putumayo", dada la necesidad de incentivar la actividad económica en Mocoa, se estableció reducir a cero la tarifa para la obtención de la matrícula mercantil, y su renovación durante la vigencia 2018, para las empresas que se constituyan en jurisdicción del municipio, sin consideración al monto de los activos o el patrimonio del comerciante, a excepción de las cooperativas de ahorro y crédito y financieras. Asimismo, se estableció el otorgamiento de beneficios tributarios a los aportantes de la contribución parafiscal para la promoción del turismo ubicados en el municipio, con el fin de que esto redunde en la reactivación de la industria y en la generación de empleo asociado. En tal sentido, se excluye a los operadores de turismo del pago de la contribución parafiscal de que trata la Ley 1101 de 2006, hasta el 31 de diciembre de 2018.

Con respecto a la plaza de mercado, centro de la comercialización de los productos agropecuarios en el municipio, y uno de los principales focos del desastre, se indicó que se habían caracterizado 312 personas que estaban trabajando dentro de la misma, quienes a través del Departamento de prosperidad Social (DPS) recibirían una línea de apoyo y serían categorizados para entregarles unos recursos para poder hacer capital semilla y así reconstruir su negocio (MinComercio, Industria y Turismo, 2017). Adicionalmente, en el Decreto 731 de 2017 del Ministerio de Hacienda y Crédito Público, "Por el cual se dictan medidas tributarias dentro del estado de emergencia económica, social y ecológica en el Municipio de Mocoa, Departamento del Putumayo", se establece un tratamiento tributario especial para algunos bienes producidos o comercializados en el Municipio de Mocoa, con el propósito de estimular la demanda interna, contrarrestar los posibles impactos directos sobre la inflación e incrementar el consumo local de los bienes que se producen o comercializan en la zona.

El decreto en mención disponía exención de IVA hasta el 31 de diciembre de 2017 de alimentos, calzado, prendas de vestir, materiales de construcción, electrodomésticos y gasodomésticos vendidos en Mocoa. También, según el concepto emitido por la DIAN el 30 de abril de 2019, este decreto hacía aplicable la tarifa (0) en retención y en renta, a las empresas y establecimientos de comercio domiciliados en el municipio de Mocoa, no así a las empresas que tengan puntos de venta en otros municipios del país. 
Por otra parte, en la Circular Normativa Externa No. 007 del 18 de abril de 2017, el Fondo Nacional de Garantías S.A (FNG), indicó que, junto con la Banca de las Oportunidades, en 2012 se diseñó un programa especial de garantía que buscaba apoyar a los microempresarios afectados por cualquier evento o fenómeno natural, quienes debían acreditar su condición ante la entidad que el gobierno nacional designe como encargado del registro o censo de los afectados. Para el caso particular de la avalancha de Mocoa en 2017, el Ministerio de Comercio, industria y Turismo era una entidad válida para dicha acreditación, en razón a la evaluación de los microempresarios afectados y la consecuente base de datos de empresarios que requerían apoyo por las afectaciones del fenómeno natural.

El Fondo Nacional de Garantías S.A- FNG propuso además un instrumento para apoyar a las Mipymes de Mocoa en la Circular normativa externa No.009 del 24 de abril de 2017. Mediante la creación de los productos especiales Reactivación Pymes Mocoa y Reactivación Microempresas Mocoa se buscaba facilitar el acceso al crédito por parte de los empresarios y liberarlos de la obligación de la primera anualidad de la comisión que corresponde a las operaciones reservadas entre el $1^{\circ}$ de mayo y el 31 de diciembre de 2017. Las empresas que podrían beneficiarse de este instrumento eran Mipymes con domicilio en Mocoa, con activos totales hasta de 30.000 SMMLV pertenecientes a todos los sectores económicos exceptuando las actividades agropecuarias primarias (Ver tabla 1).

Tabla 1: Productos financieros del instrumento propuesto por el FNG en la circular 009 del 2017

\begin{tabular}{|c|c|c|c|c|}
\hline Tipo de empresa & $\begin{array}{l}\text { Código de } \\
\text { producto y } \\
\text { modalidad }\end{array}$ & $\begin{array}{l}\text { Nombre del } \\
\text { producto }\end{array}$ & $\begin{array}{c}\text { Cobertura de } \\
\text { Garantía del FNG }\end{array}$ & $\begin{array}{c}\text { Reclamación pago } \\
\text { y recuperación }\end{array}$ \\
\hline $\begin{array}{c}\text { Mipymes (personas } \\
\text { jurídicas o naturales) } \\
\text { Microempresas } \\
\text { (personas jurídicas o } \\
\text { naturales) }\end{array}$ & $\begin{array}{c}\text { EMP089 } \\
\text { Automática }\end{array}$ & $\begin{array}{c}\text { Reactivación } \\
\text { Pymes Mocoa } \\
\text { Reactivación } \\
\text { Microempresas } \\
\text { Mocoa }\end{array}$ & $\begin{array}{l}\text { Hasta el } 50 \% \\
\text { sobre el saldo } \\
\text { insoluto de } \\
\text { capital de crédito }\end{array}$ & $\begin{array}{c}\text { Con recuperación } \\
\text { de cartera } \\
\text { Sin recuperación de } \\
\text { cartera }\end{array}$ \\
\hline
\end{tabular}

Fuente: Fondo Nacional de Garantías (2018). Elaboración propia

De acuerdo con información suministrada por la Superintendencia Financiera de Colombia (2017) sobre el seguimiento de los alivios otorgados por parte de las entidades financieras a los damnificados registrados en la Unidad Nacional para la Gestión del Riesgo de Desastres de Colombia y que aceptaron las ayudas ofrecidas por parte de las entidades, se destaca que dentro de los alivios acordados se realizaron acuerdos de pago, condonación, congelamiento, crédito nuevo, reestructuración y refinanciación.

El análisis de la situación financiera de los damnificados después del alivio otorgado en septiembre del 2017, muestra la diferencia entre el monto sobre el cual se practicó la ayuda financiera para el total de los créditos en la modalidad comercial por más de 2 mil millones de pesos, lo que es equivalente a una reducción del 17.52\% de la deuda. Los créditos en la modalidad de leasing fueron los que experimentaron una mayor reducción, pues la reducción de la deuda alcanzó el 45\%. En contraste, los créditos en la modalidad de vivienda apenas sintieron un alivio del $0.11 \%$. En cuanto al monto de los microcréditos estos se redujeron en un 16.55\% (Ver Tabla 2). 
Tabla 2: Cartera del municipio de Mocoa después de la implementación de ayudas financieras

\begin{tabular}{ccccc}
\multicolumn{5}{c}{ por modalidad en el 2017 (en millones de pesos) } \\
\hline Modalidad & Monto & Saldo a Sep. 2017 & Diferencia & Porcentaje \\
\hline Comercial & $\$ 15809$ & $\$ 13039$ & $\$ 2769$ & $17.52 \%$ \\
Consumo & $\$ 38036$ & $\$ 36215$ & $\$ 1820$ & $4.79 \%$ \\
Leasing & $\$ 13.76$ & $\$ 7.50$ & $\$ 6.25$ & $45.46 \%$ \\
Microcrédito & $\$ 14824$ & $\$ 12370$ & $\$ 2454$ & $16.55 \%$ \\
Vivienda & $\$ 9640$ & $\$ 9629$ & $\$ 10.38$ & $0.11 \%$ \\
\hline Total, general & $\$ 78324$ & $\$ 71262$ & $\$ 7061$ & $9.015 \%$ \\
\hline
\end{tabular}

Fuente: Comité de damnificados (2017). Elaboración propia

La modalidad de microcrédito recibió una ayuda financiera significativa, solo estuvo en porcentaje por debajo de las concesiones sobre los créditos comerciales y leasing. Los alivios otorgados a dicha modalidad fueron mayormente realizados a través de acuerdos de pago, con una diferencia de más de 875 millones de pesos entre el monto sobre el que se practicó el acuerdo y el saldo a septiembre del 2017. Una diferencia similar se dio por medio de créditos nuevos con más de 825 millones de pesos, mientras que el alivio menos usado fue la reestructuración de la deuda. Además, las entidades financieras otorgaron condonaciones de microcréditos por 10 millones de pesos (Ver Tabla 3).

Tabla 3: Ayudas financieras (microcrédito) de las Instituciones Financieras en Mocoa Posterior a la tragedia de marzo del 2017 (millones de pesos)

\begin{tabular}{|c|c|c|c|}
\hline \multirow{3}{*}{$\begin{array}{c}\text { Modalidad } \\
\text { Acuerdo de Pago }\end{array}$} & \multicolumn{2}{|c|}{ Microcrédito } & Diferencia \\
\hline & Monto & $\$ 3.309,68$ & \\
\hline & Saldo a Sep. de 2017 & $\$ 2.344,34$ & $\$ 875,34$ \\
\hline Condonación & $\begin{array}{l}\text { Monto } \\
\text { Saldo a Sep. de } 2017\end{array}$ & $\$ 10,38$ & $\$ 10,38$ \\
\hline Congelamiento & $\begin{array}{l}\text { Monto } \\
\text { Saldo a Sep. de } 2017\end{array}$ & $\begin{array}{l}\$ 935,92 \\
\$ 676,65\end{array}$ & $\$ 259,26$ \\
\hline Crédito Nuevo & $\begin{array}{c}\text { Monto } \\
\text { Saldo a Sep. de } 2017\end{array}$ & $\begin{array}{l}\$ 4.796,02 \\
\$ 3.907,34\end{array}$ & $\$ 825,67$ \\
\hline Reestructuración & $\begin{array}{c}\text { Monto } \\
\text { Saldo a Sep. de } 2017\end{array}$ & $\begin{array}{l}\$ 3.987,99 \\
\$ 3.915,55\end{array}$ & $\$ 72.44$ \\
\hline Refinanciación & $\begin{array}{c}\text { Monto } \\
\text { Saldo a Sep. de } 2017\end{array}$ & $\begin{array}{l}\$ 1.784,74 \\
\$ 1.373,79\end{array}$ & $\$ 410.95$ \\
\hline
\end{tabular}

Fuente: Comité de damnificados (2017). Elaboración propia

Por parte de Bancóldex, el 12 de septiembre de 2018 se comunicó que los empresarios y comerciantes de Guainía, Putumayo y Vichada damnificados por las lluvias, podrían acceder a 25.000 millones de pesos para responder de manera eficaz y oportuna a las necesidades de financiamiento que tienen las micro, pequeñas y medianas empresas para su recuperación productiva. El presidente de Bancóldex indicó que cada empresa podría solicitar un crédito de hasta 100 millones de pesos con un plazo de hasta 5 años y periodo de gracia a capital de hasta 1 año, la tasa de interés al intermediario financiero es de 4,5\% E.A. Con estos incentivos, se esperaba beneficiar a cerca de 4.200 empresas.

En este comunicado se menciona también que tras la avalancha de 20173.239 empresarios de Mocoa recibieron créditos, gracias a la línea especial creada en abril de 2017, con recursos del Ministerio de Comercio, Industria y Turismo. En total se desembolsaron \$25.486 millones, representados en 3.823 operaciones de crédito. La línea fue cerrada el 24 de mayo de 2018, cuando se agotaron los recursos disponibles para atenderla. 
De forma paralela, por medio del Ministerio de Agricultura y Desarrollo Rural, se destinó una nueva partida por \$2.300 millones para el plan de reconstrucción de Mocoa, con el fin de beneficiar a cerca de 300 familias campesinas víctimas de la tragedia, con proyectos productivos relacionados con avicultura y piscicultura. Esta inversión se sumaba a la ya destinada en el marco del Plan para la reconstrucción de Mocoa 2017-2022, que contemplaba más de $\$ 5.000$ millones para la activación del sector agropecuario en la región y que beneficiaría a 310 familias a través del proyecto denominado "Apoyo a Alianzas Productivas en Mocoa", que recibiría $\$ 4.017$ millones para fortalecer a 130 familias productoras de caña panelera y del sector piscícola; y del proyecto que brindaba acompañamiento técnico, herramientas e insumos y fortalecimiento socio-empresarial para iniciativas de avicultura, cítricos, plátano y aguacate.

Por otra parte, el 20 de diciembre de 2018, la Unidad Nacional para la Gestión del Riesgo de Desastres y la Alcaldía de Mocoa firmaron un convenio por más de 4.130 millones de pesos para ejecutar una obra de mitigación que beneficiaría a los habitantes del barrio El Modelo, aledaño a la plaza de mercado y uno de los más afectados por la avenida torrencial del 2017. Este convenio se dio en el marco del cumplimiento de las acciones que están enmarcadas en el Plan de Reconstrucción de Mocoa, bajo la gerencia del director de la UNGRD (UNGRD, 2018). Por parte de las entidades privadas, en mayo de 2017, se anunció que Banco WWB apoyaría microempresarios, trabajadores independientes y personas que se dedicaban a diferentes actividades productivas en Mocoa al poner en marcha un plan que incluía agilizar los trámites para la reclamación de microseguros cuyo pago ascendía a 2.805 millones de pesos, la apertura de una línea de microcrédito con un período de gracias de seis meses y prórrogas a clientes del momento con una cartera total que sumaba 262 millones de pesos (BLU RADIO, 2017).

De otro lado, en carta dirigida a la Cámara de Comercio de Putumayo con fecha del 5 de mayo de 2017, Bancamía (entidad de la fundación BBVA MicroFinanzas en Colombia) señaló las medidas adoptadas para la atención de microempresarios cuya actividad económica se había visto impactada negativamente por la emergencia. De acuerdo con lo expresado, para la fecha, Bancamía atendía en su oficina de Mocoa a cerca de 1.700 clientes microempresarios. Según la comunicación, los colaboradores de la entidad "(...) se ocuparon de la ubicación en sus lugares de residencia o en albergues, con el fin de establecer su situación y nivel de afectación, suspendiendo entre tanta toda gestión de cobro, garantizando la prestación de servicios en la oficina y brindando acompañamiento en los procesos de reclamación de pólizas de seguro adquiridas (...)" (CC Putumayo, 2017). A partir de un censo de clientes, la Junta Directiva del Banco autorizó la implementación de un plan especial de atención a los clientes de Mocoa apalancado en recursos propios de la entidad, así como en las líneas de redescuento habilitadas por Bancóldex y las líneas especiales de garantía ofrecidas por el Fondo Nacional de Garantías. El plan incluía tasas de interés inferiores a las habitualmente trabajadas, reestructuraciones y suspensión de la cobranza, también contemplaba la posibilidad de conceder refinanciaciones que incorporan nuevos recursos de crédito a clientes que pese a haber sufrido afectación total, tenían posibilidades de reactivar su unidad productiva con una inyección de capital de trabajo, todo ello dependiendo de la situación particular de cada deudor (CC Putumayo, 2017). 
Adicionalmente, la fundación BBVA Microfinanzas indicó en su página web que los microseguros se presentaron como una herramienta que permitió tener mayor capacidad de reacción a sus usuarios de Mocoa, ya que les dio la oportunidad de pagar sus deudas e hizo factible la adquisición de capital y otros materiales para la puesta en marcha de sus emprendimientos. "Ante adversidades, la inseguridad económica de las poblaciones vulnerables se manifiesta por el mayor efecto que un shock tiene sobre ellas, es decir a la carencia de recursos para protegerse ante estos imprevistos, se suma la falta de mecanismos de reacción". (Los microseguros, 2017). En este sentido, se puede apreciar que las alternativas propuestas por parte de las entidades de financiamiento se presentan como un producto que ellos mismos ofrecían, tal como lo expone BBVA MicroFinanzas: "Las soluciones de los gobiernos nacionales y locales, aun siendo necesarias, muchas veces no son suficientes, o no llegan lo bastante rápido para devolver las vidas de los damnificados. Por estas razones, la contratación de un microseguro se convierte en una opción viable y recomendable para poder afrontar este tipo de situaciones. Los microseguros permiten que, ante una catástrofe, los supervivientes se sientan parte del proceso de reconstrucción, empoderados y dueños del nuevo futuro que quieren trazar." (Los microseguros, 2017)

Finalmente, se debe destacar que en el Boletín informativo no 114 de la Unidad Nacional para la Gestión del Riesgo de Desastres, con fecha del 19 de junio de 2019, se destaca que tanto el Alcalde como la Gobernadora ante el proceso de reconstrucción de Mocoa señalaron que "(...) pese a que no ha sido fácil reconstruir la capital del Putumayo tras la emergencia del 31 de marzo de 2017, la articulación entre los gobiernos municipal, departamental y nacional ha sido fundamental para la consecución de recursos, concertación de obras y proyectos, pero fundamentalmente la participación de la comunidad tanto para la toma de decisiones, como para la ejecución de la misma reconstrucción."(p.14). No obstante, en el comunicado de prensa No 067 de la Contraloría del 21 de mayo de 2019, dicha entidad alerta sobre el incumplimiento de avance para la construcción de las viviendas urbanas, el impacto en el retraso de las obras trasciende un tema urbanístico, revictimiza a los afectados e impacta su liquidez, productividad y en consecuencia repercute en su estabilidad financiera.

\section{Las preocupaciones de la Población Afectada}

La comunidad damnificada ha manifestado en distintos escenarios que, a pesar de las estrategias y programas diseñados, las afectaciones no han sido minimizadas, ya que por ejemplo con el caso del periodo de gracia, se tiene que, terminado este tiempo, los cobros se intensificaron a pesar de la lenta recuperación del municipio, además indican que no ha habido un acompañamiento pertinente a los ciudadanos. Incluso, la comunidad ha manifestado que en algunos casos los bancos han tomado medidas agresivas para forzar el pago de los créditos. Esta situación aumenta la vulnerabilidad de la población de Mocoa, ya que en lugar contribuir a la reconstrucción de sus vidas, termina sometiendo a los afectados al sobreendeudamiento e iliquidez.

Con el propósito de vincular la apreciación y las experiencias de los damnificados de la avalancha, se realizó la "Encuesta sobre la incidencia de la avalancha de marzo del 2017 en el uso de productos y servicios microfinancieros en Mocoa" a una muestra de $140^{6}$

${ }^{6}$ El tamaño de muestra representativa $\left(\mathrm{N}^{*}\right)$ se halló teniendo en cuenta el número de damnificados registrados en el registro único de damnificados RUD $(\mathrm{DNP}, 2017)$ como tamaño de la población y utilizando la siguiente fórmula: 
personas mayores de 18 años en el municipio de Mocoa. El 62,9\% de los encuestados fueron mujeres y el 63,1\% de la muestra estaba inscrita al SISBEN nivel 1. Los niveles de escolaridad son bajos, la mayor porción de la muestra $(38,6 \%)$ indicó que realizó estudios hasta primaria, seguido del 34,3\% que indicó que realizó estudios hasta secundaria, sólo el 20,7\% de los encuestados realizó estudios de educación superior. Adicionalmente se tiene que el $42,1 \%$ de los encuestados señaló que es trabajador cuenta propia y no cuenta con empleados y el 22,1\% indicó que el dueño o socio de un negocio con al menos un empleado.

Frente a las formas de financiación a las que recurren los encuestados, el 64\% de la muestra indicó que acude a bancos comerciales, seguido por Entidades Microfinancieras y en último lugar, al gota a gota o paga diario. El Banco Agrario, Bancamía, Fundación Mundo mujer y Contactar son las entidades financieras con las que se ha relacionado mayor parte de la muestra. Además, los resultados del instrumento muestran que la mayoría de los microcréditos adquiridos por la población se destinan comenzar un negocio o a inversión en un negocio ya existente (figura 5).

Figura 5: Uso de productos y servicios microfinancieros en Mocoa

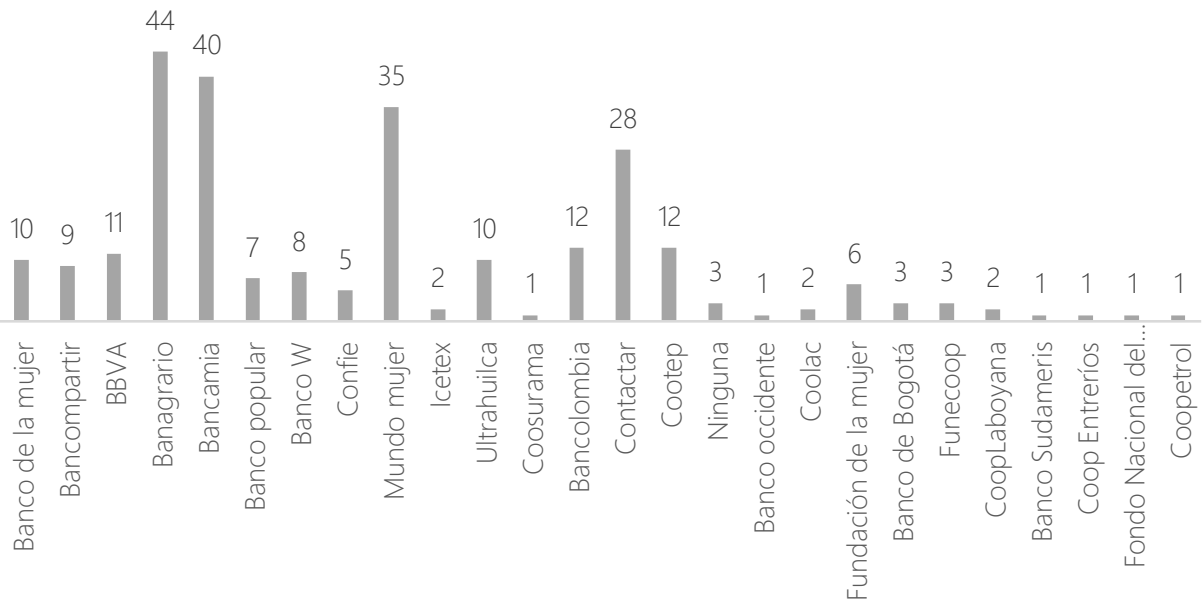

Fuente: Elaboración propia

A pesar de que la motivación social de las microfinanzas indica que deben proveer acompañamiento técnico y educación financiera continua para que los individuos usen dichos créditos como herramienta de desarrollo, el 68,6\% de los encuestados manifestó nunca recibir acompañamiento por parte de la entidad financiera y el 20,7\% afirmó que solo recibió acompañamiento al momento de adquirir el crédito (figura 6).

$N^{*}=N Z 2 p q / d 2(N-1)+Z 2 p q$

Donde $\mathrm{N}$ es el tamaño de la población; Z - corresponde al valor estandarizado en función del grado de confiabilidad de la muestra, para los fines de la presente investigación es igual a 1,96 (para dos colas) con un 95\% de confiabilidad; p es la probabilidad de éxito (95\%); q es la probabilidad de fracaso equivalente a (1-p); d es el error máximo admisible en términos de proporción, el cual oscila entre 1 y 10\% de acuerdo con las condiciones específicas de la toma de datos. 
Figura 6: Asesoría y/o acompañamiento por parte de las entidades microfinancieras

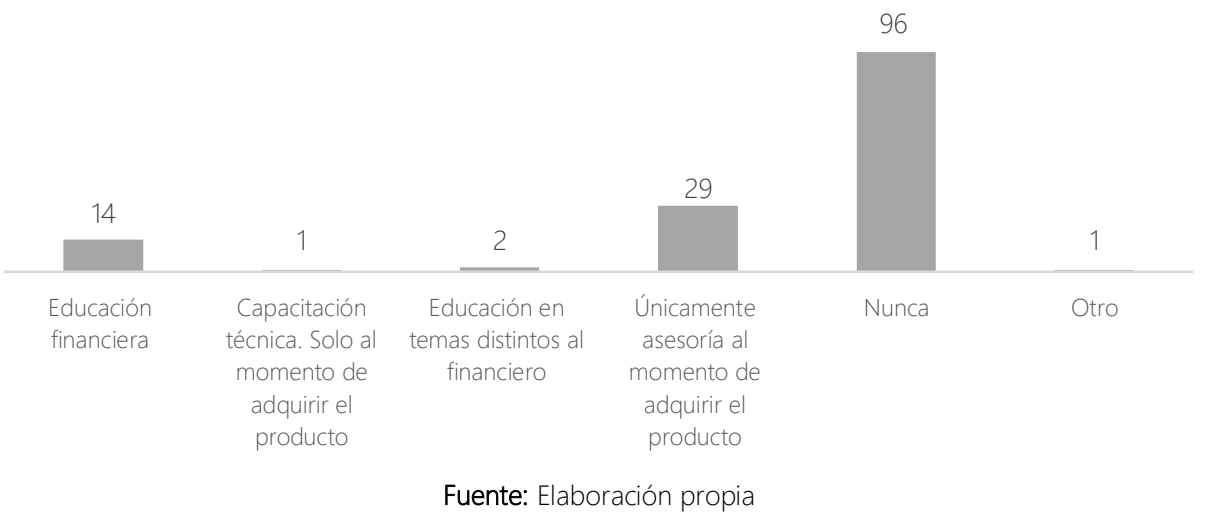

Por otra parte, al analizar el sobreendeudamiento como una de las características de las microfinanzas financiarizadas. Los resultados de la encuesta mostraron que antes de la avalancha el 48,2\% de los encuestados tenía 2 o más créditos a la vez. Dicho escenario indica que los usuarios de los servicios microfinancieros no evitan el sobreendeudamiento y este puede ser un factor determinante del declive microfinanciero.

Frente al empleo de tácticas de cobro coercitivo, como característica de las microfinanzas financiarizadas, el análisis de las encuestas refleja que, ante la morosidad, los bancos o entidades microfinancieras optan por llamadas o visitas informativas, más que por cualquier otra táctica de cobro. Sin embargo, el 23\% de las personas de la muestra ha sentido presión psicológica por parte de las entidades financieras, lo cual ha tenido repercusiones negativas en su calidad de vida.

Por otra parte, de acuerdo con los datos tomados de la SFC, el índice de morosidad en Mocoa aumentó tras la avalancha, reflejo de este índice es que antes de la avalancha ocurrida en marzo del 2017 solo el 9,4\% de las personas encuestadas había quedado en mora con sus obligaciones y tras la avalancha el 70\% manifestó haber incumplido con sus obligaciones financieras. Entre las razones por las cuales se entró en mora se encuentra principalmente la pérdida total o parcial de los negocios, locales y vivienda, sobre todo en la plaza de mercado, la disminución de las ventas posterior al evento y la lenta recuperación económica del municipio (Véase figura 7).

Figura 7: Morosidad en Mocoa

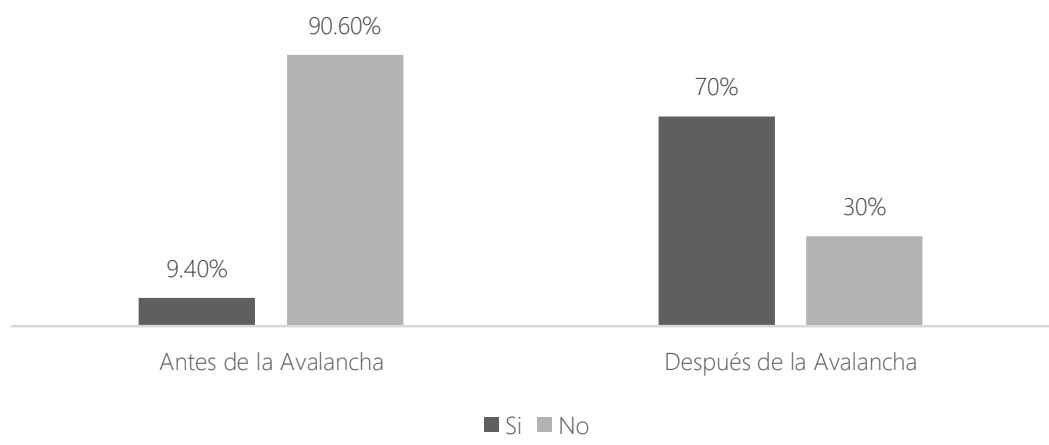

Fuente: Elaboración propia. 
Ante la pérdida de la inversión, la población manifestó la necesidad de adquirir nuevos créditos para pagar obligaciones financieras pasadas, para el consumo, gastos en educación, gastos médicos, de vivienda, personales y aquellos relacionados con el pago a proveedores y facturas del almacén. La mayoría de las personas expuso la necesidad de adquirir créditos para invertir, es decir para la restauración de sus negocios, el 29\% indicó que los nuevos créditos tuvieron el objetivo de pagar obligaciones financieras pasadas como muestra de la incidencia de la avalancha en el sobreendeudamiento de los habitantes de Mocoa. Alrededor del 29\% de las personas que debieron acudir a nuevos créditos manifestó haberlo hecho con la misma entidad con la que tenía los créditos anteriormente, el 23\% de personas en cambio adquirieron el crédito con una entidad microfinanciera distinta, y el 16\% manifestaron haber acudido a prestamistas o paga diario, cifra que supera a acudir a familiares o amigos.

Una de las razones para acudir a prestamistas gota gota después de la avalancha reside en la facilidad de acceso al crédito, y en la necesidad de responder con sus obligaciones financieras pasadas con los bancos y entidades microfinancieras. Por último, teniendo en cuenta que la Circular Externa 009 de la Superintendencia Financiera de Colombia del 5 de abril del 2017, estableció que la emergencia debía atenderse con apoyos a los damnificados por parte de las entidades bancarias, entre ellos, congelamiento de la deuda por un periodo de tiempo determinado, refinanciación, nuevos acuerdos de pago, entre otros, el $42 \%$ de los encuestados manifestaron no haber recibido alguna de estas ayudas, mientras que el $58 \%$ obtuvo beneficios, incluso recibieron más de una ayuda por parte de las entidades.

La mayoría de estas ayudas se dieron a través del congelamiento de la deuda por un periodo de 3 y 6 meses. Ninguno de los encuestados fue beneficiado con la condonación de la deuda y una mínima proporción de la muestra $(2,14 \%)$ manifestó haber recibido la disminución de los intereses. Respecto al cumplimiento de los acuerdos, el 74\% de las personas manifestó que la entidad cumplió con lo pactado. Sin embargo, dentro de los encuestados la percepción sobre los beneficios es negativa, debido a que el congelamiento y refinanciación extendía el número de cuotas y por ende los intereses que debían pagar. Pese a la situación problemática que tiene la población tras la avalancha, el $80 \%$ de la muestra está de acuerdo con la necesidad de los microcréditos como una herramienta para mejorar su situación socioeconómica después de la catástrofe, ya que consideran que al tener tasas de interés, plazos y flexibilidad mejores que el gota a gota, evitan que la población recurra a este tipo de prestamistas. Además, resaltan que, los microcréditos permiten financiar y reconstruir los pequeños negocios que son la actividad económica predominante en Mocoa. A pesar de esta apreciación, también enfatizan en la necesidad de una recuperación económica y una reconstrucción integral del municipio que les permita no solo cancelar sus obligaciones financieras sino mejorar su situación socioeconómica.

\section{Percepción de la Problemática Por Parte de las IMF y el Gobierno}

Con el propósito de ahondar en el análisis de la problemática entorno al endeudamiento con microcrédito por parte de los damnificados de Mocoa, se realizaron entrevistas de profundización con delegados de diferentes IMF del municipio y funcionarios de la Alcaldía de Mocoa durante el mes de junio de 2019. 
Desde la perspectiva del sector microfinanciero en el municipio de Mocoa, representado por cooperativas, microfinancieras y bancos, el proceso de bancarización de la región es reciente, Morales (2019) resalta que los mocoanos hasta hace muy pocos años han tenido un acercamiento a la bancarización y que en esta medida entidades microfinancieras como el Banco Bancamía han sido esenciales en familiarizar a la población con la oferta microcrediticia, no obstante, luego de las entrevistas de profundización realizadas, se percibe que las entidades microfinancieras reconocen tener participación sobre la bancarización, pero no expresan ningún procedimiento claro sobre educación financiera.

Aunque se deben resaltar excepciones como la expuesta por parte de Morales (2019), quien destacó que por parte de Bancamía se asiste a asambleas en zonas vulnerables para dar información financiera a las personas, o por parte de Rivas (2019), quien expuso que Fundación de la Mujer ofrece recursos virtuales sobre educación financiera disponibles para la población del municipio, al comunicarnos con la población, la mayoría de las personas niegan haber recibido educación financiera. Así, se puede evidenciar que, si bien se llegan a realizar acciones para dar información a la población, esta resulta ser esporádica o ineficaz. Frente a la finalidad productiva de los microcréditos, preocupa que una de las líneas de mayor importancia corresponde a los microcréditos especiales de libre inversión. Tal es el caso del Banco Popular donde Mejía (2019), destaca que como Banco el microcrédito es una categoría correspondiente a préstamos de bajo monto mas no a un servicio que esté acompañado por la implementación de la metodología microfinanciera como sí lo observa en los servicios ofertados por parte de cooperativas.

No obstante, Guzmán (2019) destaca que entidades como Cooperativa Ultrahuilca, a diferencia del sector bancario, ofertan sus servicios a los grupos sociales de mayor vulnerabilidad con el propósito de promover alternativas productivas que les permitan mejorar sus condiciones socioeconómicas. En esta línea, entidades como Bancamía, COOTEP, Cooperativa Ultrahuilca y Fundación Mundo de la Mujer destacan que realizan estudios previos al desembolso del crédito para evaluar el proyecto y así determinar la elegibilidad para financiación. Sin embargo, tal como lo reconoce Carrillo (2019), en entidades como Cooperativa Especializada en Ahorro y Crédito, no se realiza un acompañamiento de inversión, de buenas inversiones ni de buenas prácticas. Dada la ausencia de implementación de metodología microfinanciera, el único tipo de contacto que se mantienen con el deudor se activa en caso de que quede en mora con sus obligaciones. En tal caso, por medio de llamadas telefónicas y visitas se busca recordar e insistir en el pago de las cuotas. Ante este comportamiento, se puede entender la reacción de los damnificados de la avalancha ante la insistencia de los bancos para cobrar. No perciben acompañamiento por parte de la institución microfinanciera hasta que después de la avalancha, al quedar en mora con sus pagos, reciben un tratamiento insistente de cobranza, lo cual hace sentir a los damnificados presionados e intimidados en medio de un trágico contexto.

Al momento de la avalancha, las microfinancieras reconocieron haber hecho todo un proceso de reconocimiento personalizado a los damnificados para poder atender a sus necesidades, tras este proceso se implementó un periodo de gracia y refinanciación. Un caso destacado fue el realizado por parte de Bancamía, Morales (2019) afirma que se tomaron créditos de personas que habían perdido absolutamente todo. En primer lugar, se revisó si los usuarios afectados tenían seguros o microseguros, para en caso tal 
hacerlos efectivos. Luego de esto, se buscó la forma de que la herramienta de normalización tomara el 100\% de la deuda y la congelara durante 1 año, en los casos de mayor impacto. En este periodo de tiempo no se cobraban intereses ni amortización a capital, entendiendo que los afectados se encontraban en su proceso de recuperación. Una vez cumplido el periodo estipulado, la deuda volvía a estar vigente con el saldo que estaba debiendo al momento del congelamiento.

El acompañamiento brindado por parte de las IMF a los damnificados estuvo ligado a dos características: la activación de seguros adquiridos por los deudores con el fin de sanear las deudas y la cartera y la apertura de nuevos créditos, en especial a las personas que poseían negocios antes de la catástrofe. Tales opciones fueron ineficaces, toda vez que desencadenaron un proceso de sobreendeudamiento ante la incapacidad de recuperación productiva de los habitantes de Mocoa. Además, ante la calamidad presentada, los testimonios señalan que, dadas las circunstancias, los usuarios se vieron obligados a emplear el dinero prestado al consumo inmediato y no a actividades productivas. Tal situación profundiza aún más la crisis pues no existe capacidad de pago y en consecuencia el índice de morosidad en las IMF crece exponencialmente, tal como lo manifiesta Morales (2019). esde la perspectiva de los usuarios, a pesar de la implementación las medidas de mitigación implementadas por las IMF, los damnificados afirmaron que sus deudas habían crecido después de la avalancha y concluían que no se había cumplido el periodo de gracia. Una explicación a esta problemática reside en la asimetría de la información entre las entidades financieras y los usuarios y la debilidad e incluso ausencia de educación financiera.

A pesar de que se cumplieron dos de las recomendaciones de la SFC con la implementación del congelamiento de la deuda, no se evidenció la implementación de una disminución en los intereses cobrados, por el contrario, según la muestra encuestada, en algunos casos, después de la refinanciación, estos aumentaron. En contraste, en las acciones emprendidas en Bangladesh o Pakistán, tras los desastres naturales expuestos previamente, se puede evidenciar que la disminución de intereses se convierte en una medida de gran importancia para que las entidades microfinancieras puedan atender la emergencia de la catástrofe y permitir a las personas mejorar su situación financiera para así sobrellevar la catástrofe. Por otra parte, desde la perspectiva de la Alcaldía Municipal, desde la catástrofe, el municipio ha vivido un estancamiento económico y productivo, que se evidencia entre otros, en la caída en el recaudo público desencadenado en parte por las medidas de mitigación implementadas. Carlos Julio Ramírez, secretario financiero de Mocoa, expone que dada la disminución en el recaudo del impuesto predial y de industria y comercio, la alcaldía no ha podido generar el gasto necesario que conlleve a fomentar el empleo ni inversión para la restauración del municipio, pues esta caída en el gasto ha ralentizado la ejecución de obras de infraestructura necesarias para la reactivación productiva y de proyectos de reactivación económica.

Tras la avalancha, el comercio, hotelería, puentes y el acueducto fueron los más afectados. Los puentes conectan la zona residencial con la comercial, y como la catástrofe aisló el centro del municipio, los comerciantes han sufrido no solo la pérdida de gran parte de sus activos, sino también la falta de dinamismo. A la fecha de la presente investigación, la infraestructura no había sido restaurada en su totalidad, ni se había logrado crear un ambiente de confianza en la población, lo cual ha incentivado la migración de actores 
productivos y en consecuencia la salida de capital del municipio. Dado tal contexto económico, así los bancos brinden más créditos para que la población emprenda nuevas alternativas productivas, esto no garantiza el saneamiento de la situación financiera de la población, ya que la economía de Mocoa no permite tener estabilidad en el flujo de ingresos. Esto anclado al sobreendeudamiento antes mencionado, describe un incipiente escenario de financiarización.

Una de las acciones apoyadas por la alcaldía para ayudar a los damnificados, en conjunto con los bancos, fue el intento de condonar deudas. Aunque se intentó sanear la situación financiera de las personas no se pudo realizar una labor significativa por la falta de ingresos tributarios que llevaron a dejar de lado estas acciones. Adicionalmente, en alianza con la Cámara de Comercio de Putumayo (CCP) se buscó apoyar aquellos negocios inscritos a la misma, con el fin de apalancar su restauración y ayudarlos con sus deudas. Sin embargo, esta ayuda no tuvo un efecto significativo debido a la poca cantidad de inscritos en la Cámara de Comercio, en comparación con la totalidad de los negocios en Mocoa.

Debe tenerse en cuenta también que el día anterior a la catástrofe de 2017 se vencía el término de inscripción de los negocios ante la CCP, así que muchas personas se les venció el plazo, pensaban hacerlo más adelante o simplemente se les olvidó, pero a la hora de realizar esta ayuda todos esos negocios inscritos no la recibieron. Ante el panorama descrito, la situación de Mocoa no es prometedora. Los bancos reforzaron sus planes austeros, pero con sus préstamos han generado problemas de sobreendeudamiento y aunque el propósito del microcrédito es la inversión productiva, el contexto socioeconómico dificulta la generación de beneficios de tal manera que se logre solventar la situación financiera precaria de muchos de los afectados. De allí que los damnificados se encuentren refinanciando, obteniendo más créditos y perpetuando y profundizando sus deudas.

\section{CONCLUSIONES}

La avalancha de Mocoa expuso la vulnerabilidad económica del municipio, la informalidad y la ausencia de políticas de competitividad se hicieron evidentes una vez ocurrida la catástrofe. En este contexto, escenarios de sobreendeudamiento, precariedad en la educación financiera de los habitantes, y ausencia total de la implementación de metodología microfinanciera fueron expuestos evidenciando leves manifestaciones de un proceso de financiarización. A pesar de los esfuerzos documentados y establecidos por medio de medidas reglamentarias, entre otros, con el fin retornar a la normalidad a Mocoa tras la catástrofe, estos no son claramente apreciables. Por el contrario, la percepción local manifiesta un inconformismo con las medidas implementadas, en particular con las medidas llevadas a cabo por parte de IMF como mecanismo transitorio ante la incapacidad de los damnificados de cumplir con sus obligaciones financieras.

Los deudores damnificados en el municipio de Mocoa carecen de la capacidad para poder recuperar sus actividades productivas, los plazos de congelamiento de la deuda han resultado insuficientes y la asimetría de la información exacerba la frustración de los deudores. En este sentido, el sobreendeudamiento con entidades formales o incluso con prestamistas "gota a gota" sobresale como el mecanismo por medio del cual se cubren 
transitoriamente obligaciones financieras, pero lo que realmente se avecina es un caso crítico de incapacidad de pago pues no se cuenta con un soporte productivo que permita cumplir con las obligaciones financieras. En este sentido, el rol gubernamental debe enfocarse en incentivar la reactivación económica del municipio y fortalecer los lineamientos regulatorios de la prestación de servicios microfinancieros, para que bajo esta figura se aplique la metodología que permita que los recursos otorgados a través del microcrédito sean realmente el apalancamiento necesario para la consecución de proyectos productivos.

De parte de las IMF resulta imprescindible una autorregulación que acompañada por un cercano seguimiento estatal impida el sobrendeudamiento, una verdadera aplicación del acompañamiento a las iniciativas productivas y un reforzamiento y acondicionamiento de acuerdo con el perfil de los microempresarios de la oferta de microseguros, para de esta manera, desde el mismo portafolio de servicios microfinancieros se esté preparado ante la ocurrencia de un desastre natural. Por último, se hace un llamado tanto a las entidades públicas como privadas, a replantear un programa que permita una negociación de los microcréditos pertenecientes a damnificados que perdieron todo su capital productivo y que a la fecha no han podido reestablecer sus actividades. Esta negociación debe ir de la mano con acompañamiento para la reactivación económica para de esta manera retornar al verdadero propósito de las microfinanzas, apalancar proyectos productivos para la superación de la pobreza.

\section{REFERENCIAS}

Asomicrofinanzas. (2018). Microcrédito en Colombia. 10 Foro Nacional de Asomicrofinanzas, 20. Bogotá.

Banca de las Oportunidades. (2017). Cobertura de oficinas marzo de 2017.

BLU RADIO. (17 de mayo de 2017). Banco WWB apoyará microempresarios de Mocoa. Blu Radio.

Banca de las Oportunidades \& Superintendencia Financiera de Colombia (s.f). Reporte inclusión financiera 2013.

Banca de las Oportunidades \& Superintendencia Financiera de Colombia (2017). Reporte inclusión financiera 2016.

Bateman, M. (2013). La era de las microfinanzas: destruyendo las economías desde abajo. Revista Ola Financiera, 6 (15)

Carrillo, D (13 de junio de 2019) Cooperativa Especializada en Ahorro y Crédito, oficina Mocoa (A. Rodríguez, Entrevistadora) Putumayo, Colombia.

C.C Putumayo. (2015). Cámara de Comercio de Putumayo. Estudios e investigaciones. Recuperado en Julio de 2019 de http://ccputumayo.org.co/site/category/estudios-y-diagnosticos/

C.C Putumayo. (2016). Cámara de Comercio de Putumayo. Estudios e investigaciones. Recuperado en Julio de 2019 de http://ccputumayo.org.co/site/category/estudios-y-diagnosticos/

C.C Putumayo. (2017). Cámara de Comercio de Putumayo. Estudios e investigaciones. Recuperado en Julio de 2019 de http://ccputumayo.org.co/site/category/estudios-y-diagnosticos/

C.C Putumayo. (mayo de 2017). Cámara de Comercio de Putumayo. Recuperado el abril de 2019, de Respuesta Bancamía: http://ccputumayo.org.co/site/wpcontent/uploads/2017/04/Respuesta-BANCAMIA.pdf

C.C Putumayo. (2018). Cámara de Comercio de Putumayo. Estudios e investigaciones. Recuperado en Julio de 2019 de http://ccputumayo.org.co/site/category/estudios-y-diagnosticos/ 
Comité de damnificados (2017). Solicitud de información del Senador Alberto Castilla a la Superintendencia Financiera de Colombia. Documento no publicado.

DNP (2017). Documento Conpes 3904: Plan para la reconstrucción del municipio de Mocoa 2017 2022. Consejo Nacional de Política Económica y Social. Recuperado de: https://colaboracion.dnp.gov.co/CDT/Conpes/Econ\%C3\%B3micos/3904.pdf

Duque, G. (2017). El siniestro de Mocoa, designio de la imprevisión.

Los microseguros, u. m. (2017). Fundación BBVA MicroFinanzas. Recuperado el marzo de 2019, de http://www.fundacionmicrofinanzasbbva.org/los-microseguros-macro-apoyo/

FNG. (18 de abril de 2017). Fondo Nacional de Garantías S.A. Recuperado el abril de 2019, de Circular $\begin{array}{lllll}\text { Normativa } & \text { Externa } & 007 & \text { No } & \end{array}$ http://www.fng.gov.co/ES/Documentos\%20\%20Circulares/CNE-007-2017.pdf

FNG. (24 de abril de 2017). Fondo Nacional de Garantías S.A. Recuperado en abril de 2019, de Circular Normativa Externa No. 009 de https://www.fing.gov.co/ES/Documentos\%20\%20Circulares/CNE-009-2017.pdf

Gutiérrez Goiria, J., \& Unceta Satrustegui, K. (2015). Compatibilidad o conflicto entre objetivos sociales y financieros de las microfinanzas: debates teóricos y evidencia empírica. Revista Innovar Journal, 25(1Spe), 103-120. https://doi.org/10.15446/innovar.v25n1Spe.53362

Guzmán, D (13 de junio de 2019) Cooperativa Utrahuilca, oficina Mocoa. (S. Salamanca, Entrevistadora) Putumayo, Colombia.

Klein, Naomi. (2007). La doctrina del shock, el auge del capitalism del desastre. Paidós. Argentina.

Kumar, A. \& Newport, J. (2007). Microfinance and rural housing. In Indian Association for Savings and Credit (IASC), 18 pages.

Kunt, A., Klapper, L., Singer, D., Ansar, S., \& Hess, J. (2017). La base de datos Global Findex 2017.

Mejia, M. (13 de junio de 2019). Banco Popular oficina Mocoa. (A. Rodríguez, Entrevistadora) Putumayo, Colombia.

MinComercio, Industria y Turismo. (11 de mayo de 2017). Ministerio de Comercio, Industria y Turismo. Recuperado el abril de 2019, de Avanzan acciones de MinComercio para reactivación comercial en Mocoa: http://qa. mincit.gov.co/loader. php?IServicio=Publicaciones\&id=38277

Ministerio de Hacienda. (2017). Boletín No. 052 Colombia concluye con éxito las Reuniones Anuales del BID en Paraguay. Recuperado el abril de 2019, de http://www. minhacienda.gov.co/HomeMinhacienda/ShowProperty?nodeld=\%2FOCS\%2FP MH CP WCC-064472\%2F\%2FidcPrimaryFile\&revision=latestreleased

Morales, F (14 de junio de 2019). Bancamía oficina Mocoa. (M. González, Entrevistadora) Putumayo, Colombia.

Municipio de Mocoa. (s.f.). Corpoamazonía. Recuperado el 2019, de http://www.corpoamazonia.gov.co/region/Putumayo/Municipios/Ptyo Mocoa.html

PNUD (2015). Perfil productivo de Mocoa-Putumayo. Recuperado de https://issuu.com/pnudcol/docs/perfil_productivo_mocoa

Ramírez, C (2019) Alcaldía de Mocoa (N. Ramírez Entrevistadora) Putumayo, Colombia.

Ramírez, N. (2018). Microfinanzas rurales en Colombia ¿Alternativa de financiamiento virtuosa o incipiente proceso de financiarización? Universidad Nacional de Colombia. Bogotá D.C, Colombia.

Rivas, R (14 de junio de 2019). Fundación de la mujer oficina Mocoa. (M.Salamanca, Entrevistadora) Putumayo, Colombia.

Shoji, M. (2010). Does contingent repayment in microfinance help the poor during natural disasters? Journal of Development Studies, 46(2), 191-210. https://doi.org/10.1080/00220380902952381 
Shoji, M. (2012). Evaluation of contingent repayments in microfinance: Evidence from a natural disaster in Bangladesh. The Developing Economies, 50(2), 116-140. https://doi.org/10.1111/j.17461049.2012.00161.x

Soto Esquivel, R. (2017). Microfinanzas. Resultados financieros y sociales: México y Perú. Ola Financiera, 10(27), 22.

Ullah Khan, H., \& Kurosaki, T. (2007). Vulnerability of Microfinance to Natural Disasters: Evidence from the 2005 Pakistan Earthquake. Hitotsubashi University.

UNGRD (2018). Seguimiento de acciones en Mocoa-Putumayo. Recuperado de: http://www.camara.gov.co/sites/default/files/2018-09/ANEX0\%201\%20\%20UNGRD.pdf 